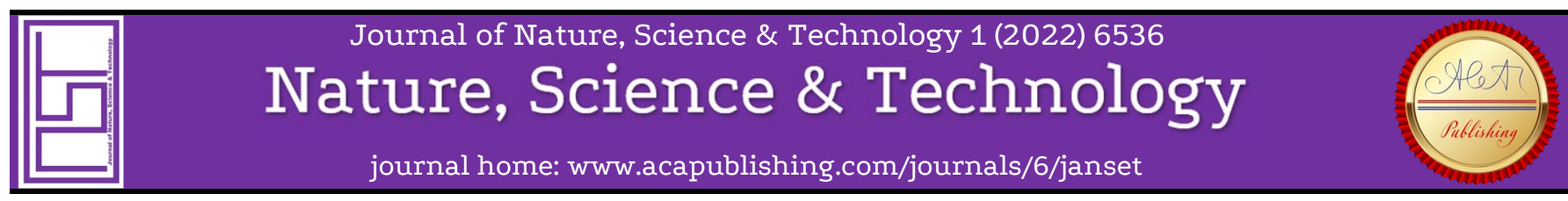

Research Article

\title{
Preparation of Dietary Fiber Concentrate from Tunisian Lemon (Citrus Limon L.) by-Products: Physico-Chemical, Functional and Antioxidant Properties
}

\author{
Manel Masmoudi ${ }^{*}{ }^{(i)}$, Fatma Abbès ${ }^{1}$, Souhail Besbes ${ }^{1}$ (D) , Christophe Blecker $^{2}$ (D) Hamadi Attia $^{1 \text { (D) }}$ \\ ${ }^{1}$ Université de Sfax, Laboratoire Analyses, Valorisation et Sécurité des Aliments, Ecole Nationale d'Ingénieurs de Sfax, Route \\ de Soukra, 3038 Sfax, Tunisia \\ ${ }^{2}$ Université de Liège-Gembloux Agro-Bio Tech, Unité de Technologie des Industries Agro-alimentaires, Passage des Déportés, 2 , \\ B-5030 Gembloux, Belgium
}

\section{Keywords}

Lemon by-product,

Fiber concentrate,

Physico-chemical,

Antioxidant activity,

Functional properties.

\begin{abstract}
Dietary fibers constitute an important element of a healthy diet. This study is a contribution to valorize Tunisian lemon (Citrus limon L.) by-products (LB) by preparation of a lemon fiber concentrate (LFC). The suitability of this by-product as a source of dietary fiber for food enrichment was investigated. Lemon fiber concentrate was prepared by LB washing in water at $90{ }^{\circ} \mathrm{C}$ for $5 \mathrm{~min}$ and then characterized by studying its physico-chemical, functional and antioxidant properties, in comparison with the original LB.

The extraction method led to a total dietary fiber yield of $54.42 \mathrm{~g} / 100 \mathrm{~g}$. LFC had higher content in total fibers than LB (71.20 versus $63.87 \mathrm{~g} / 100 \mathrm{~g}$ dry matter (DM), respectively), with predominance of the insoluble fraction $(53.58 \mathrm{~g} / 100 \mathrm{~g}$ DM). LFC had also better functional properties, with higher water holding capacity (13.92 versus $8.51 \mathrm{~g} / \mathrm{g}$, respectively), swelling capacity (14 versus $8.75 \mathrm{ml} / \mathrm{g}$, respectively) and oil retention property (6.6 versus $4.43 \mathrm{~g} / \mathrm{g}$, respectively). LFC had high content in bioactive compounds, particularly for phenolics (561.09 mg GAE/100 g DM) and flavonoids (408.42 mg QE/ $100 \mathrm{~g} \mathrm{DM}$ ), which gave it good antioxidant properties (antiradical activity: $45.57 \%$ and reducing power: 0.18 ). The results of this study suggested that LFC may have potential applications for food enrichment.
\end{abstract}

\section{Introduction}

In Tunisia, lemon and lime production reached 54000 tons in 2019 [1] During the lemon juice extraction process, important quantities of pulp, seeds and peels are generated. These by-products contain appreciable levels of valuable substances such as vitamins and antioxidant compounds [2, 3].

Several studies have tried to valorize lemon by-products as a source of pectin [4], polyphenols [5] and dietary fibers (DF) [2, 5] and to convert citrus by-products into food ingredients and other value-added materials $[6,7]$.

Currently, many industries tried to find new sources of fibers, valuable in many food industries. Dietary fibers are divided into two categories: soluble (SDF) and insoluble (IDF) ones. The source of fiber is very important. In fact, differences in constitution of plant cells, as well as the structure of fibers could affect their characteristics [8] Cereals are well known as important sources of dietary fibers. However, citrus fruit fibers have higher nutritional quality, higher SDF/IDF ratio, lower caloric content, higher functional properties, and stronger antioxidant capacity [9].

Dietary fiber intake is beneficial for preventing many diseases. We can cite hemorrhoids, cancer, cardiovascular problems as well as the treatment of obesity [8]. DF could be used, from a technological point of view, as ingredients for water binding, fat replacing, and gelling [2, 10].

Furthermore, oxidation of different food products is a serious problem encountered in many food industries. Development of this phenomenon can be avoided or retarded by using antioxidants. Currently, most of the employed antioxidants are synthetic (BHT: butylated-hydroxytoluene and BHA: butylated-hydroxyanisole) and are known to have toxic and carcinogenic effects on human health [8]. Therefore, there is currently a growing interest to find cheap, renewable and abundant sources of natural antioxidant compounds, as alternatives to prevent deterioration of fats and oils [8]. Thus, lemon by-product is interesting due to its important fiber content as well as its antioxidant capacity [2].

Food industries are always looking for fiber ingredients. Several investigations have studied the possibility of preparing dietary fiber powders from many agricultural by-products, such as jujube [11], date [11], and orange [5]. In fact, Masmoudi et al. (2021) [11] prepared a fiber concentrate from jujube fruit, and reported high fiber ( $89 \mathrm{~g} / 100 \mathrm{~g} \mathrm{DM})$ and phenolic content. Borchani et al. $(2010,2012)[12,10]$ extracted date fiber powders from eleven date varieties and found good functional and nutritional properties. Further studies have investigated other by-products such as apple and citrus fruits [2,5]. However, to the best of our knowledge, there are few studies on lemon fiber concentrates, reporting a detailed characterization, covering antioxidant, functional as well as physico-chemical aspects.

In this sense, the aims of the present study were firstly to prepare a dietary fiber concentrate from lemon by-products (LB) of mixed Tunisian lemon varieties, and secondly to determine physicochemical, functional and antioxidant properties of the prepared lemon fiber concentrate (LFC), in comparison to the original byproduct, in order to evaluate its potential use as a natural ingredient in many food formulations.

\section{Experimental procedure}

2.1. Plant material and sample preparation 
Three batches of lemon (Citrus limon L.) by-products were supplied by a fruit beverage industry (Zina, Sfax, Tunisia). This by-product was generated after processing of mixed lemon varieties from Nabeu region. It consists of the peel, the pulp and the pips. For each batch, the pips were discarded, and the remaining matter was divided into two shares. The first was dried in a ventilated oven (WTB binder, Tuttlingen, Germany) at $50{ }^{\circ} \mathrm{C}$ for 24 hours and then ground to a fine powder to be analyzed (LB). The second share was used for preparation of lemon fiber concentrate.

\subsection{Fiber extraction}

Fibers were extracted from fresh lemon by-products. The extraction was carried out on the three batches of lemon by-product. Each one was agitated in hot water at $90{ }^{\circ} \mathrm{C}$, in a water bath at a ratio of $(1 / 5$; $\mathrm{w} / \mathrm{v}$ ) for $5 \mathrm{~min}$ [2]. The mixture was then filtrated using a cloth (pore size: $0.318 \mathrm{~mm}$ ), for insoluble residue separation. Following this process, three fiber concentrate batches were obtained, dried at $50^{\circ} \mathrm{C}$ for 24 hours; then milled in a grinder (GRINDOMIX, Germany) and preserved at $4{ }^{\circ} \mathrm{C}$ until analysis.

\subsection{Evaluation of extraction yields}

The extraction yield of lemon fiber concentrates is the mathematical expression of the quantity of the product obtained, starting from the initial quantity of lemon by-product. The yield was expressed in different manners: dry matter, total dietary fiber (TDF), IDF, and SDF yields [12]

\subsection{Physico-chemical properties of LF and LFC}

Dry matter and ash contents were analyzed following AOAC methods (1995) [13]. Titrable acidity was determined by titration with $\mathrm{Na} \mathrm{OH}(0.1$ N) to $\mathrm{pH}=8.1 \pm 0.2[14]$.

Fat content was determined by extraction with hexane using Soxhlet apparatus [15]. Protein was analyzed according to the Kjeldhal method. Factor 6.25 was used for conversion from total nitrogen to crude protein [13]. Total soluble sugars were determined according to the phenol-sulfuric acid method [16].

Insoluble and soluble dietary fibers were determined according to the AOAC enzymatic-gravimetric method [17]. Total dietary fiber (TDF) was expressed as $\mathrm{g} / 100 \mathrm{~g}$ dry samples. Pectin content was analyzed using a colorimetric method [18]. Crude cellulose content was determined according to Weende method [13].

Water activity (aw) was analyzed at $25^{\circ} \mathrm{C}$ (Novasina aw Sprint TH-500 apparatus, pfäffikon, Switzerland) at $25^{\circ} \mathrm{C}$. pH was measured using a $\mathrm{pH}$ meter (METTLER TOLEDO. MP220) at $20{ }^{\circ} \mathrm{C}$ after mixing samples with water at a ratio of 1:4 and 1:10 (w/v), respectively for fresh LB and dried LFC [13]

\subsection{Color measurement}

Color measurement of LFC was carried out using a colorimeter Mini Scan XETM (Hunter Lab, In., Reston, VA, USA). (L*, $a^{*}$, and $b^{\star}$ ) were measured, with:

$L^{*}$ : from 0 (black) to 100 (white).

$\mathrm{a}$ : from -100 (greenness) to +100 (redness)

$\mathrm{b*}$ : from -100 (blueness) to +100 (yellowness).

\subsection{Functional properties}

Water holding capacity (WHC) and oil holding capacity (OHC) of the LB and LFC were analyzed according to the methods described by Jia et al. (2019) [19] and Abdul-Hamid and Luan (2000) [20], respectively. Values were expressed as fixed water/g and fixed oil/g sample, respectively.

Swelling capacity (SC) was measured following the method of Robertson et al. (2000) [21]. SC was expressed as volume (ml) occupied/g of sample.

Emulsifying capacity (EC) was analyzed according to Abdul-Hamid and Luan (2000) [20]. The EC was expressed as a percentage of the total mixture that remained emulsified after centrifugation.

2.7. Determination of phenolic, carotenoid contents and antioxidant properties
Extraction of phenolic compounds was carried out according to $\mathrm{Li}$ et al. [22] with some modifications. $5 \mathrm{~g}$ of LB or LFC powders were extracted for $1 \mathrm{~h}$ of continuous agitation with $25 \mathrm{ml}$ of ethanol (85\%) at room temperature in the dark. The mixture was centrifuged at $5000 \mathrm{~g}$ for $15 \mathrm{~min}$. The pellet was extracted twice with $10 \mathrm{ml}$, then, 5 $\mathrm{ml}$ of ethanol for $30 \mathrm{~min}$ under identical conditions. The supernatants were collected after centrifugation, concentrated by evaporation of the solvent, using a rotary evaporator, and stored at $4{ }^{\circ} \mathrm{C}$. This extract was used for determination of total phenolic content, flavonoids, and antioxidant properties.

Total phenolic content was analyzed by the Folin-Ciocalteu method according to Dewanto et al. (2002) [23]. Results were expressed as gallic acid equivalent (GAE)/g DM.

Total flavonoids were determined according to the method adopted by Koley et al. (2018) [24]. Total flavonoid content was measured using the standard curve for quercetin solutions and expressed as mg QE (quercetin equivalents)/100 $\mathrm{g}$ of dry weight.

Extraction of total carotenoids (TC) was performed according to the method of Kuti (2004) [25] with slight modifications. In brief, $5 \mathrm{~g}$ of sample and $25 \mathrm{ml}$ of hexane/acetone/ethanol (50:25:25, v/v) were homogenized with a blender. After centrifugation at $5000 \mathrm{~g}$ at $5{ }^{\circ} \mathrm{C}$ for $5 \mathrm{~min}$, the top layer of hexane was recovered and transferred to a 25 $\mathrm{ml}$ volumetric flask. The volume of recovered hexane was adjusted to $25 \mathrm{ml}$ with hexane. Absorbance was measured at $450 \mathrm{~nm}$ using a spectrophotometer. Total carotenoids were calculated according to AlFarsi et al. (2005) [26], using the following Eq. (1), and expressed as $\mathrm{mg} / 100 \mathrm{~g}$ of fresh weight.

$\mathrm{TC}=\left(\mathrm{Ab} \times \mathrm{V} \times 10^{6}\right) /(\mathrm{A} 1 \% \times 100 \mathrm{G})$

Ab: absorbance at $450 \mathrm{~nm}$;

$\mathrm{V}$ : the total extract volume;

A 1\%: the extinction coefficient for a $1 \%$ carotenoids mixture at 2500 G: the weight of the sample (g).

Free radical scavenging activities (FRSA) of LB and LFC were evaluated using the DPPH (2,2-diphenyl-1-picrylhydrazyl free radical) assay according to Ruth et al. (2018) [27]. Antioxidant activity was calculated using Eq. (2):

$\% \mathrm{FRSA}=\left[\mathrm{A}_{\text {control }}-\mathrm{A}_{\text {sample }} / \mathrm{A}_{\text {control }}\right] \times 100$

Where $A_{\text {control }}$ is the absorbance of the control and $A_{\text {sample }}$ is the absorbance of the sample extracts.

Samples reducing powers were determined using the method of Yildirim et al. (2001) [28]. Results were expressed in absorbance at 700 $\mathrm{nm}$. Increased reaction mixture absorbance indicated increased reducing power.

\subsection{Statistical analyses}

The experiment was conducted according to a randomized complete block design. All analytical determinations were performed at least in triplicate for each batch of LF or LFC. Results were expressed as the mean \pm standard deviation $(x \pm$ S.D.). Statistical analyses were assessed using a statistical software program (STATISTICA, Release 5.0 Stat Soft Inc. Talsa, OK). Duncan's test was performed at the level of $p<0.05$ to evaluate the significance of differences between mean values.

\section{Results and discussion}

\subsection{Evaluation of extract yields of LFC}

Table 1 presents different expressions of extraction yields of the obtained LFC. The dry matter yield was in the range of $43 \mathrm{~g} / 100 \mathrm{~g}$. Similar values were reported by Wachirasiri et al. (2009) [29] for banana fiber (37.2 g/100g). However, Borchani et al. (2010) [12] found much lower values for date fiber concentrates (5.66 to $10 \mathrm{~g} / 100 \mathrm{~g}$ ). This difference could be probably due to less soluble fibers and to sugar loss in hot water during the extraction procedure adopted in our study. 
Total dietary fiber yield was $\sim 54 \mathrm{~g} / 100 \mathrm{~g}$, indicating that about 46 $\mathrm{g} / 100 \mathrm{~g}$ of $\mathrm{DF}$ was lost during the described extraction method. This fraction was represented mainly by SDF which could be lost in hot water. This result was confirmed by soluble fiber yield reaching only $36.5 \mathrm{~g} / 100 \mathrm{~g}$. Finally, the major recovered fraction was that of insoluble fiber with $64.20 \mathrm{~g} / 100 \mathrm{~g}$.

Table 1. Evaluation of extraction yields ( $\mathrm{g} / 100 \mathrm{~g}$ ) of lemon fiber concentrate from lemon by-product

\begin{tabular}{lc}
\hline Yields & Values \\
\hline Dry matter & $43.27 \pm 0.91$ \\
Total dietary fiber & $54.42 \pm 1.45$ \\
Insoluble dietary fiber & $64.20 \pm 1.71$ \\
Soluble dietary fiber & $36.50 \pm 1.24$ \\
\hline
\end{tabular}

\subsection{Physico-chemical analyses}

Table 2 illustrates the physico-chemical characteristics of LB and LFC. As regards to LFC, it shows domination of fibers with $71.2 \mathrm{~g} / 100 \mathrm{~g} \mathrm{DM}$, with increased content compared to the LB $(63.87 \mathrm{~g} / 100 \mathrm{~g})$. The same tendency was observed for the insoluble fraction which increased from 40.19 to $53.58 \mathrm{~g} / 100 \mathrm{~g}$, respectively for LB and LFC. Cellulosic content represented almost half of IDF content, with $19.54 \mathrm{~g} / 100 \mathrm{~g}$ in the case of LFC. However, soluble fibers decreased from 23.68 to 17.62 $\mathrm{g} / 100 \mathrm{~g} \mathrm{DM}$. This result could be due to the washing step using hot water, which decreased soluble components content and concentrated insoluble fractions.

Soluble fibers were mainly presented by pectin $(17.03 \mathrm{~g} / 100 \mathrm{~g}$ in the case of LFC). This polysaccharide is used in the food industry as a gelling agent and also has important applications in the pharmaceutical industry.

Table 2. Physico-chemical properties of the fresh lemon by-product and its corresponding fiber concentrate powder

\begin{tabular}{lcc}
\hline Component & LB & LFC \\
\hline Moisture (\%) & $84.26 \pm 0.01^{\mathrm{a}}$ & $6.05 \pm 0.06^{\mathrm{b}}$ \\
Ash $^{*}$ & $3.41 \pm 0.02^{\mathrm{a}}$ & $2.54 \pm 0.03^{\mathrm{b}}$ \\
Fat* $^{*}$ & $2.65 \pm 0.09^{\mathrm{a}}$ & $2.05 \pm 0.06^{\mathrm{b}}$ \\
Protein* $_{\text {Soluble sugars* }}$ & $9.47 \pm 0.10^{\mathrm{a}}$ & $6.98 \pm 0.29^{\mathrm{b}}$ \\
TDF & $14.22 \pm 0.07^{\mathrm{a}}$ & $9.23 \pm 0.33^{\mathrm{b}}$ \\
IDF & $63.87 \pm 0.45^{\mathrm{a}}$ & $71.20 \pm 0.28^{\mathrm{b}}$ \\
SDF & $40.19 \pm 0.25^{\mathrm{a}}$ & $53.58 \pm 0.7^{\mathrm{b}}$ \\
(IDF/SDF) ratio & $23.68 \pm 0.19^{\mathrm{a}}$ & $17.62 \pm 0.98^{\mathrm{b}}$ \\
Pectin* & 1.69 & 3.04 \\
Cellulose* & $21.90 \pm 0.42^{\mathrm{a}}$ & $17.03 \pm 0.53^{\mathrm{b}}$ \\
pH & $19.54 \pm 0.4^{\mathrm{a}}$ & $24.81 \pm 0.95^{\mathrm{b}}$ \\
Acidity & $3.06 \pm 0.01^{\mathrm{a}}$ & $3.94 \pm 0.02^{\mathrm{b}}$ \\
Water activity & $45.7 \pm 0.11^{\mathrm{a}}$ & $35.64 \pm 0.15^{\mathrm{b}}$ \\
\hline
\end{tabular}

LB: lemon by-product, LFC: lemon fiber concentrate, TDF: total

dietary fibers, IDF: insoluble dietary fibers, SDF: soluble dietary fibers *: g/100g dry matter; **: meq/100g

Data are expressed as means \pm S.D. $(n=3)$. Means within the same row with different letters are significantly different $(p<0.05)$.

Insoluble/soluble dietary fiber (IDF/SDF) ratio is an indicator of nutritional quality. Fruit and vegetable are characterized by lower IDF/SDF ratio in comparison to that of cereals [30]. According to Figuerola et al. (2005) [5], fibers having IDF/SDF ratio close to 2 are suitable to use them as food ingredient and to exert good physiological effects. In this study, IDF/SDF ratio was near this value, with about 3 for the lemon fiber concentrate. The obtained results were near those reported by Lopez-Vargas et results were near those reported by Lopez-Vargas et al. (2013) [31] for passion fruit albedo fibers. These authors found 71.79; 52.34 and $19.45 \mathrm{~g} / 100 \mathrm{~g} \mathrm{DM}$, respectively for TDF, IDF and SDF (IDF/SDF ratio of 2.69).

Figuerola et al. (2005) [5] reported similar results for TDF content (68.3 $\mathrm{g} / 100 \mathrm{~g} \mathrm{DM})$, in the case of a fiber concentrate obtained from Fino lemon variety. However, fibers were less balanced, with a high
(IDF/SDF) ratio of 9.9. Furthermore, LFC have higher TDF content than fiber concentrates obtained from other fruits: e.g. for passion fruit pulp and seeds (53.51 g/100g DM) [32], and orange ( $37 \mathrm{~g} / 100 \mathrm{~g} \mathrm{DM})$ [14].

LFC was characterized by low protein, ash and fat contents, with respectively $6.98 ; 2.54$ and $2.05 \mathrm{~g} / 100 \mathrm{~g}$ and presented low moisture ( $6 \mathrm{~g} / 100 \mathrm{~g}$ ) and water activity (0.116).

Similar results were found by Figuerola et al. (2005) [5] for Eureka lemon variety. These authors reported 6.79; 1.89 and $3.47 \mathrm{~g} / 100 \mathrm{~g} \mathrm{DM}$, respectively, for proteins, fat and ash. Furthermore, Lario et al. (2004) [2] reported similar aw and $\mathrm{pH}$ values for fiber powder from Fino variety (0.13 and 3.98, respectively).

Thus, physico-chemical results obey the recommendations of Larrauri, (1999) [32] who reported that dietary fibers must have a total fiber content higher than $50 \mathrm{~g} / 100 \mathrm{~g}$, low content of lipids and moisture (< $9 \mathrm{~g} / 100 \mathrm{~g})$, low caloric value, and neutral flavor and taste.

\subsection{Color}

Table 3 presents color parameters $\left(L^{*}, a^{*}\right.$ and $\left.b^{*}\right)$ for the dried LFC. Results showed that drying didn't induce browning of the LFC. This was demonstrated by the negative value of $a^{*}(-0.34)$, the high lightness $\left(L^{*}=85.68\right)$ and the $b^{*}$ value (28.21) responsible for yellow color. In fact, according to Lario et al. (2004) [2], brown is defined as a yellow color with low lightness and a positive value of $a^{*}$ component. These authors obtained brownish lemon fiber powder after drying at $65{ }^{\circ} \mathrm{C}$ for $24 \mathrm{~h}\left(L^{*}=64.91 ; a^{*}=4.47\right.$ and $\left.b^{*}=25.89\right)$. This could be explained by drying temperature as well as the lemon variety and composition. Furthermore, Aleson-Carbonell et al. (2005) [6] reported darker lemon fibers $\left(L^{*}=59.27 ; a^{*}=8.21\right.$ and $\left.b^{*}=22.93\right)$.

Table 3. Color parameters of lemon fiber concentrate

\begin{tabular}{lc}
\hline & Values \\
\hline $\mathrm{L}^{*}$ & $85.68 \pm 0.16$ \\
$\mathrm{a}^{*}$ & $-0.34 \pm 0.01$ \\
$\mathrm{~b}^{*}$ & $28.21 \pm 0.02$ \\
\hline & Data are expressed as means \pm S.D. $(\mathrm{n}=3)$.
\end{tabular}

\subsection{Functional properties}

Table 4 illustrates the functional properties of the studied products. LFC reached a higher value of WHC than that of the original byproduct, with respectively 13.92 and $8.51 \mathrm{~g} / \mathrm{g}$ ). This increase could be explained by improvement in TDF content, as well as a decrease in soluble sugars, fat, and proteins (Table 2) after extraction in hot water. Raghavendra et al., (2004) [33] reported that the hydration capacity of dietary fibers could be negatively influenced by high content in proteins and fat.

The observed WHC in the present study was similar to that found by Lario et al. (2004) [2] who reported about 13 for lemon fibers. However, WHC value was higher than those found by some authors in other fruit fiber concentrates. In fact, Borchani et al. (2012) [10] reported values ranging from 3.39 and $6.77 \mathrm{~g} / \mathrm{g}$ for dates fibers. Furthermore, Aleson-Carbonell et al. (2005) [6] obtained lower values for lemon (6.5 $\mathrm{g} / \mathrm{g}$ ) fibers.

Table 4 shows that SC of the LFC was also improved, in comparison to $\mathrm{LB}$, after the washing step in water. In fact, it increased from 8.75 to $14 \mathrm{ml} / \mathrm{g}$, respectively. This value was higher than those reported in the literature for some fiber concentrates: e.g. for lemon var. Eureka (7.32 $\mathrm{ml} / \mathrm{g}$ ) [5] and dates (from 5.69 to $\sim 9 \mathrm{ml} / \mathrm{g}$ ) [10].

The high hydration capacity of the LFC indicates that it could be used in many food formulations, such as bakery or cooked meat products. Indeed, such food needs hydration and viscosity development [31].

Oil holding capacity was also evaluated. As for LFC, values were in the average of $6.6 \mathrm{~g} / \mathrm{g}$, indicating higher OHC than LB $(4.43 \mathrm{~g} / \mathrm{g})$. This property is beneficial for flavor retention and technological yield increases [34]. In the literature, the reported values were much lower 
for dietary fiber preparations from passion fruits $(2.03 \mathrm{~g} / \mathrm{g})$, mango $(1.6$ $\mathrm{g} / \mathrm{g})$ and lemon $(1.3 \mathrm{~g} / \mathrm{g})[5,30,31]$.

Contrarily to the previous functional properties, the emulsifying capacity of the LFC was low (10.5\%). In a previous study, Borchani et al. (2012) [10] found values ranging between 1.56 and $12.87 \%$ for fibers from different date varieties. The obtained value in this study showed that LFC could not be considered as a good emulsifier. Indeed, products having stability indices lower than 50\% could not be considered as good emulsifiers [10]. However, despite its low EC, the addition of LFC could ameliorate food stability, particularly fat and emulsion-rich products.

Table 4. Functional properties of lemon by-product and its corresponding fiber concentrate

\begin{tabular}{lcc}
\hline & LB & LFC \\
\hline WHC (g water/g) & $8.51 \pm 0.19^{\mathrm{a}}$ & $13.92 \pm 0.11^{\mathrm{b}}$ \\
SC (ml water/g) & $8.75 \pm 0.28^{\mathrm{a}}$ & $14.00 \pm 0.35^{\mathrm{b}}$ \\
OHC (g oil/g) & $4.43 \pm 0.21^{\mathrm{a}}$ & $6.62 \pm 0.31^{\mathrm{b}}$ \\
EC $(\%)$ & $6.5 \pm 0.51^{\mathrm{a}}$ & $10.50 \pm 0.70^{\mathrm{b}}$ \\
\hline
\end{tabular}

LB: lemon by-product, LFC: lemon fiber concentrate, WHC: water holding capacity; SC: swelling capacity; OHC: oil holding capacity; EC: emulsifying capacity

Results are expressed as mean $\pm \operatorname{SD}(n=3)$; Means within the same row with different letters are significantly different $(p<0.05)$.

\subsection{Total polyphenols, flavonoids and carotenoid contents}

Phenolic compounds present many biological effects, such as reducing the risk of heart disease, cancer, cataracts, etc. [26].

Total phenolic contents of the lemon by-product and its corresponding fiber concentrate, are summarized in table 5. LB had higher total phenolic content than that of LFC (645.98 and $561.09 \mathrm{mg}$ of gallic acid $/ 100 \mathrm{~g}$ DM, respectively). This difference could be explained by diffusion of these compounds in the water during extraction, as well as oxidation of polyphenolic contents under high temperatures (90 ${ }^{\circ} \mathrm{C}$ ). Ramful et al. (2010) [35] studied total phenolic content in the peel of twenty-one varieties of citrus fruits from Mauritius. They reported values ranging from 188.2 to $766.6 \mathrm{mg}$ of gallic acid $/ 100 \mathrm{~g}$ DM. Other authors studied four citrus species from Brazil [36] and found that the amount of total phenolics in peels ranged from 310.18 to $575.06 \mathrm{mg}$ catechin equivalent/ $100 \mathrm{~g}$ of fresh weight (FW). These levels are comparable to those found in the present study.

In the case of LFC, values found in this study were lower than those reported by Ubando-Rivera et al. (2005) [37] who found 10.55 and 19.90 $\mathrm{mg}$ gallic acid / $\mathrm{g}$ of dietary fiber concentrates from Mexican and Persian lemon. This difference could be explained by various factors such as variety, geographic origin and the use of different extraction and analytical methods.

Total flavonoid content is shown in table 5 . The highest level was found in LB (470.16, versus $408.42 \mathrm{mg}$ of quercetin/ $100 \mathrm{~g} \mathrm{DM}$ for LFC). This difference could be explained by the oxidation of flavonoids under high temperatures $\left(90^{\circ} \mathrm{C}\right)$. These results were higher than those reported by Wang et al. (2011) [38] who found $54.09 \mathrm{mg}$ of rutin $/ 100 \mathrm{~g}$ DM, for Citrus sulcata peel. These differences might be due to variations between extraction methods and to the studied cultivars.

In general, flavonoids are considered among the most important phenolic compounds, contributing to antioxidant activity. These compounds have many biological and chemical activities. We can cite radical scavenging properties, protection against coronary diseases, antitumor, antimicrobial, and anti-inflammatory activities [39].

LB possessed significantly higher carotenoid content than LFC, with respectively 3.98 and $2.17 \mathrm{mg} / 100 \mathrm{~g}$ (Table 5). This may be due to loss of carotenoids in water during extraction and oxidation of these compounds under high temperatures $\left(90{ }^{\circ} \mathrm{C}\right)$. Some authors have shown that $ß$-carotene is water-soluble and sensitive to heat and oxidation [40].
Table 5. Total polyphenols, flavonoids and carotenoid contents of lemon by-product and its corresponding fiber concentrate

\begin{tabular}{lcc}
\hline & \multicolumn{1}{c}{ LB } & \multicolumn{1}{c}{ LFC } \\
\hline TPC $^{*}$ & $645.98 \pm 1.82^{\mathrm{a}}$ & $561.09 \pm 1.25^{\mathrm{b}}$ \\
TF $^{\star *}$ & $470.16 \pm 0.9^{\mathrm{a}}$ & $408.42 \pm 1.46^{\mathrm{b}}$ \\
Carotenoids $^{\star * *}$ & $3.98 \pm 0.028^{\mathrm{a}}$ & $2.17 \pm 0.036^{\mathrm{b}}$ \\
\hline
\end{tabular}

LB: lemon by-product, LFC: lemon fiber concentrate, TPC: total phenolic content, TF: total flavonoids

*mg GAE (Gallic acid equivalent)/100g DM; **mg QE (quercetin equivalent)/100g DM; ***: mg/100g of fresh weight

Results are expressed as mean $\pm \mathrm{SD}(n=3)$; Means within the same row with different letters are significantly different $(p<0.05)$.

In comparison to other products, LB and LFC could be considered as good sources of carotenoids. Indeed, Al-Farsi et al. (2005) [26] studied carotenoid content in eight fruits. They found values ranging from 0.02 to $2.26 \mathrm{mg} / 100 \mathrm{~g} \mathrm{FW}$, respectively, in strawberries and mandarins.

\subsection{Antioxidant activity}

The antioxidant activity may be due to different mechanisms. We can cite free radical scavenging, prevention of chain initiation, hydrogendonation, decomposition of peroxides, reducing capacity and metal ion chelation, prevention of continued hydrogen abstraction, and it can act as a substrate for radicals [41].

As shown in table 6, it is noticed that studied products exhibited potential FRSA at a concentration of $50 \mu \mathrm{g} / \mathrm{ml}$. In fact, a high value was observed in the case of lemon by-product. This result was probably associated with total phenolic compounds, flavonoids, and carotenoid contents.

A positive correlation was observed between DPPH radical scavenging activity and total phenolics $\left(R^{2}=0.998\right.$, data not shown). This indicates that this property may be attributed to these compounds.

The FRSA of phenolic compounds is generally explained by their redox properties and hydrogen donating ability. This activity depends on the concentration of phenolic compounds as well as hydroxylation and polymerization degrees [42].

Table 6. Antioxidant capacity of lemon by-product, lemon fiber concentrate and BHA

\begin{tabular}{lccc}
\hline & LB & LFC & BHA \\
\hline FRSA (\%) & $50.44 \pm 0.64^{\mathrm{a}}$ & $45.57 \pm 0.62^{\mathrm{b}}$ & $96.42 \pm 0.57^{\mathrm{c}}$ \\
Reducing power & $0.21 \pm 0.03^{\mathrm{a}}$ & $0.18 \pm 0.05^{\mathrm{a}}$ & $0.521 \pm 0.007^{\mathrm{b}}$
\end{tabular}

LB: lemon by-product, LFC: lemon fiber concentrate, BHA: butylatedhydroxyanisole, FRSA: free radical scavenging activity

Results are expressed as mean $\pm \operatorname{SD}(n=3)$; Means within the same row with different letters are significantly different $(p<0.05)$.

Significant $(p<0.05$ ) linear correlation was also found between flavonoids and DPPH-FRSA ( $\mathrm{R}^{2}=0.998$; data not shown) in one hand, and between carotenoids and DPPH-FRSA ( $\mathrm{R}^{2}=0.758$; data not shown) on the other hand. This indicates that flavonoids are one of the main compounds responsible for the scavenging effect of LB and LFC.

Reducing power assay was used to evaluate the ability of antioxidants to donate electrons. Analysis of the studied samples at a concentration of $5 \mu \mathrm{g} / \mathrm{ml}$ resulted in absorbance of 0.21 and 0.18 respectively, for LB and LFC (Table 6). As can be seen, no significant difference ( $p>0.05$ ) was noted between OFC and OB. However, these values were significantly lower $(p<0.05)$ than that of the standard (BHA). The reducing capacity may serve as an indicator of potential antioxidant activity. Antioxidant activity increased proportionally with contents in total phenolics and flavonoids: a linear relationship between reducing power values and total polyphenol and flavonoid contents was found $\left(R^{2}=0.998\right.$ and $R^{2}=0.997$, respectively; data not shown). This suggests that these compounds (total phenolic and flavonoid compounds) contribute very importantly to the reducing 
power of the studied samples. Our results were in agreement with those of other authors [43].

\section{Conclusion}

The prepared dietary fiber concentrate, obtained from lemon byproducts, represents a suitable material for food enrichment. The extraction method used in this work yielded a lemon fiber concentrate with a high TDF content, mainly the insoluble fraction. Compared with the original by-product, the LFC was characterized by a light color and better functional properties, particularly WHC, SC and OHC. Furthermore, lemon fiber concentrate showed important levels of polyphenols and flavonoids having good antioxidant potential.

These findings suggest that preparation of such fiber-rich powder from processing industry by-products can result in adding value to many food formulations such as texturizing, viscosity development and water and oil retention.

Future work should focus on studying the possibility of adding LFC to some oil-rich foods such as spreads, in order to study its effect on functional (mainly oil retention properties) as well as antioxidant stability of the formulated product.

\section{Acknowledgements}

The authors are thankful to "Zina" industry (Sfax) for supplying lemon by-product.

\section{Funding}

This research was supported by the Ministry of Higher Education and Scientific Research, Tunisia.

\section{Declaration of Conflict of Interests}

The authors declare that there is no conflict of interest. They have no known competing financial interests or personal relationships that could have appeared to influence the work reported in this paper.

\section{References}

FAOSTAT, Statistical databases of FAO. Food and Agriculture Organization of the United Nations, Rome, (2021).

Lario, Y., Sendra, E., García-Pérez, J., Fuentes, C., SayasBarberá, E., Fernández-López, J., Perez-Alvarez, J. A. Preparation of high dietary fiber powder from lemon juice byproducts. Innovative Food Science and Emerging Technology 5 (2004) 113-117.

Kim, J.W., Lee, B. C., Lee, J.H., Nam, K. C., Lee, S.C., Effect of electron-beam irradiation on the antioxidant activity of extracts from Citrus unshiu pomaces. Radiation Physics and Chemistry 77 (2008) 87-91.

Masmoudi, M., Besbes, S., Blecker, C., Attia, H., Preparation and characterization of jellies with reduced sugar content from date (Phoenix dactylifera L.) and lemon (Citrus limon L.) by-products. Fruits 65 (2010) 21-29.

Figuerola, F., Hurtado, M. L., Estévez, A. M., Chiffelle, I., Asenjo, F., Fiber concentrates from apple pomace and citrus peel as potential fiber sources for food enrichment. Food Chemistry 9 (2005) 395-401.

[6.] Aleson-Carbonell L., Fernandez-Lopez J., Pérez-Alvarez J.A., Kuri V. Characteristics of beef burger as influenced by various types of lemon albedo. Innovative Food Science and Emerging Technology 6 (2005) 247-255.
Fu, J.-T., Chang, Y.-H., Shiau, S.-Y., Rheological, antioxidative and sensory properties of dough and Mantou (steamed bread) enriched with lemon fiber. LWT - Food Science and Technology 61 (2015) 56-62.

Rehman, Z., Citrus peel extract-a natural source of antioxidant. Food Chemistry 99 (2006) 450-454.

Fernandez-Lopez, J., Fernandez-Gine's, J.M., AlesonCarbonell, L., Sendra, E., Sayas-Barbera, E., Pérez-Alvarez, J.A., Application of functional Citrus by-products to meat products. Trends in Food Science and Technology 15 (2004) 176-185.

[10.] Borchani, C., Besbes, S., Masmoudi, M., Bouaziz, M. A., Blecker, C., Attia, H. Influence of Oven-Drying Temperature on Physicochemical and Functional Properties of Date Fibre Concentrates. Food Bioprocess Technology 5 (2012) 15411551.

Masmoudi, M., Yaich, H., Borchani, M., Mbarki, R., Attia, H., Chemical, physical and sensory characteristics of biscuits enriched with jujube (Zizyphus lotus L.) flour and fiber concentrate. Journal of Food Science and Technology 58 (2021) 1411-1419.

Borchani, C., Besbes, S., Blecker, C., Masmoudi, M., Baati, R., Attia, H., Chemical properties of 11 date cultivars and their corresponding fiber extracts. African Journal of Biotechnology 9 (2010) 4096-4105.

[13.] AOAC, Official Methods of Analysis, 15th Ed., Association of Official Analytical Chemists, Washington DC., (1995).

[14.] Grigelmo-Miguel, N., Martin-Belloso, O., Characterization of dietary fiber from orange juice extraction. Food Research International 31 (1999) 355-361.

[15.] AOAC, Official Methods of Analysis, 16th, Washington DC., (1997)

[16.] Dubois, M., Giles, K. A., Hamilton, F. K., Rebers, P. A., Smith, F., Colorimetric method for determination of sugars and related substances. Analytical Chemistry 628 (1956) 350-356.

Prosky, L., Asp, N. G., Schweizer, T. F., Devries, J. W., Furda, I., Determination of insoluble, soluble and total dietary fiber in foods and food products: interlaboratory study. Journal Association of Official Analytical Chemists 71 (1988) 10171023.

[18.] Englyst, H. N., Quigley, M. E., Hudson, G. J., Determination of dietary fiber as non starch polysaccharides with gaz-liquid chromatographic or spectrometric measurement of constituent sugars. Analyst 119 (1994) 1497-1509.

[19.] Jia, M. Y., Chen, J. J., Liu, X. Z., Xie, M. Y., Nie, S., Chen, Y. $\mathrm{Xie}, \mathrm{J} ., \mathrm{Yu}, \mathrm{Q}$., Structural characteristics and functional properties of soluble dietary fiber from defatted rice bran obtained through Trichoderma viride fermentation. Food Hydrocolloids 94 (2019) 468-474.

[20.] Abdul-Hamid, A., Luan, Y. S., Functional properties of dietary fibre prepared from defatted rice bran. Food Chemistry, 68 (2000) 15-19.

21.] Robertson, J. A., de Monredon, F. D., Dysseler, P., Guillon, F., Amadò, R., Thibault, J. F., Hydratation properties of dietary fiber and resistant starch: A European collaborative study. LWT - Food Science and Technology 33 (2000) 72-79.

[22.] Li, B.B., Smith, B., Hossain, Md. M. Extraction of phenolics from citrus peels. I. Solvent extraction method. Separation and Purification Technology 48 (2006) 182-188. 
[23.] Dewanto, V., Wu, X., Adom, K., Liu, R. H., Thermal processing enhances the nutritional value of tomatoes by increasing total antioxidant activity. Journal of Agricultural and Food Chemistry 50(2002) 3010-3014.

[24.] Koley, T.K., Maurya, A., Tripathi, A., Singh, B.K., Singh, M., Bhutia, T.L., Tripathi, P.C., Singh, B., Antioxidant potential of commonly consumed underutilized leguminous vegetables. International Journal of Vegetable Science 25 (2018) 362-372.

[25.] Kuti, J.O., Antioxidant compounds from four Opuntia cactus pear fruit varieties. Food Chemistry 85 (2004) 527-533.

Al-Farsi, M., Alasalvar, C., Morris, A., Baron, M., Shahidi, F., Comparison of antioxidant activity, anthocyanins, carotenoids, and phenolics of three native fresh and sundried date (Phoenix dactylifera L.) varieties grown in Oman. Journal of Agricultural and Food Chemistry 53 (2005) 75927599.

Ruth, O., Hamid, N., Ishmael, C., Hamid, N., Vernonia cinerea leaves as the source of phenolic compounds, antioxidants, and anti-diabetic activity using microwaveassisted extraction technique. Industrial Crops and Products 122 (2018) 533-544.

Yildirim, A, Mavi, A, Kara, A. A, Determination of antioxidant and antimicrobial activities of Rumex crispus L. extracts. Journal of Agricultural and Food Chemistry 49 (2001) 4083-4089.

Wachirasiri, P., Julakarangka, S., Wanlapa, S. The effects of banana peel preparations on the properties of banana peel dietary fiber concentrate. Songklanakarin Journal of Science and Technology 31 (2009) 605-611.

[30.] Vergara-Valenciaa, N., Granados-Pe'reza, E., AgamaAcevedoa, E., Tovarb, J., Rualesc, J., Bello-Pe'rez, L. A., Fiber concentrate from mango fruit: Characterization, associated antioxidant capacity and application as a bakery product ingredient LWT - Food Science and Technology 40 (2007) 722-729.

[31.] López-Vargas, J.H., Fernández-Lópe, J., Pérez-Ālvare, J.A., Viuda-Martos, M., Chemical, physico-chemical, technological, antibacterial and antioxidant properties of dietary fiber powder obtained from yellow passion fruit (Passiflora edulis var. flavicarpa) co-products. Food Research International 51 (2013) 756-763

Larrauri, J.A., New approaches in the preparation of high dietary fiber powders fruit by-products. Trends in Food Science and Technology 10 (1999) 3-8.

Raghavendra, S. N., Rastogi, N. K., Raghavarao, K. S. M. S. Tharanathan, R. N., Dietary fiber from coconut residue: effects of different treatments and particle size on the hydration properties. European Food Research Technology 218 (2004) 563-567.

Besbes, S., Ghorbel, R., Ben Salah, R., Masmoudi, M., Jedidi, F., Attia, H., Blecker, C. Date fiber concentrate: Chemical compositions, functional properties and effect on quality characteristics of beef burgers. Journal of Food and Drug Analysis 18 (2010) 8-14.

Ramful, D., Bahorun, T., Bourdon, E., Tarnus, E., Aruoma, O. I., Bioactive phenolics and antioxidant propensity of flavedo extracts of Mauritian citrus fruits: Potential prophylactic ingredients for functional foods application. Toxicology 278 (2010) 75-87.
Barros, H.R.M., Ferreira, T.A.P.C., Genovese, M.I., Antioxidant capacity and mineral content of pulp and peel from commercial cultivars of citrus from Brazil. Food Chemistry 134 (2012) 1892-1898.

[37.] Ubando-Rivera, J., Navarro-Ocaǹa, A., Valdivia-López, M.A., Mexican lime peel: Comparative study on contents of dietary fiber and associated antioxidant activity. Food Chemistry 89 (2005) 57-61.

[38.] Wang, A.Y., Zhou, M.Y., Lin, W.C., Antioxidative and antiinflammatory properties of Citrus sulcata extracts. Food Chemistry 124 (2011) 958-963.

[40.] Gong, H., Deng, G., Han, C., Ning, X., Process optimization based on carrot powder color characteristics. Engineering in Agriculture, Environment and Food 8 (2015) 137-142.

[41.] Mao, L., Pan, X., Que, F., Fang, X., Antioxidant properties of water and ethanol extract from hot air-dried and freezedried daylily flowers. European Food Research Technology 222 (2006) 236-24.

[42.] Moure, A., Cruz, J.M., Franco, D., Dominguez, J.M., Sineiro, J., Dominguez, H., Núnez, M.J., Parajó, J.C., Natural antioxidants from residual sources. Food Chemistry 72 (2001) 145-171.

[43.] Fawole, O.A., Opara, U.L., Theron, K.I., Chemical and phytochemical properties and antioxidant activities of three pomegranate cultivars grown in South Africa. Food and Bioprocess Technology 5 (2011) 2934-2940.

\section{How to Cite This Article}

Masmoudi, A., Abbès, F., Besbes, S., Blecker, C. and Attia, H., Preparation of dietary fiber concentrate from Tunisian lemon (Citrus limon L.) by-products: Physicochemical, functional and antioxidant properties, Journal of Nature, Science \& Technology, 1(2022), 1-6. https://doi.org/10.36937/janset.2022.6536 